\title{
Application of Sentinel-1B Polarimetric Observations to Soil Moisture Retrieval Using Neural Networks: Case Study for Bare Siberian Chernozem Soil
}

\author{
Konstantin Muzalevskiy ${ }^{1, *}$ and Anatoly Zeyliger ${ }^{2}$ D \\ 1 Laboratory of Radiophysics of the Earth Remote Sensing, Kirensky Institute of Physics Federal Research \\ Center KSC Siberian Branch Russian Academy of Sciences, Krasnoyarsk 630090, Russia \\ 2 Department of Applied Informatics, Russian State Agrarian University-Moscow Timiryazev Agricultural \\ Academy, Moscow 127550, Russia; azeiliguer@mail.ru \\ * Correspondence: rsdkm@ksc.krasn.ru
}

Citation: Muzalevskiy, K.; Zeyliger,

A. Application of Sentinel-1B

Polarimetric Observations to Soil

Moisture Retrieval Using Neural Networks: Case Study for Bare Siberian Chernozem Soil. Remote Sens. 2021, 13, 3480. https://doi.org/ $10.3390 /$ rs13173480

Academic Editor: Yang Hong

Received: 9 August 2021

Accepted: 25 August 2021

Published: 2 September 2021

Publisher's Note: MDPI stays neutral with regard to jurisdictional claims in published maps and institutional affiliations.

Copyright: (c) 2021 by the authors. Licensee MDPI, Basel, Switzerland. This article is an open access article distributed under the terms and conditions of the Creative Commons Attribution (CC BY) license (https:/ / creativecommons.org/licenses/by/ $4.0 /)$.

\begin{abstract}
Sentinel-1 is currently the only synthetic-aperture radar, which radar measurements of the earth's surface to be carried out, regardless of weather conditions, with high resolution up to 5-40 m and high periodicity from several to 12 days. Sentinel- 1 creates a technological platform for the development of new globally remote sensing algorithms of soil moisture, not only for hydrological and climatic model applications, but also on a single field scale for individual farms in precision farming systems used. In this paper, the potential of soil moisture remote sensing using polarimetric Sentinel-1B backscattering observations was studied. As a test site, the fallow agricultural field with bare soil near the Minino village $\left(56.0865^{\circ} \mathrm{N}, 92.6772^{\circ} \mathrm{E}\right)$, Krasnoyarsk region, the Russian Federation, was chosen. The relationship between the cross-polarized ratio, reflectivity, and the soil surface roughness established $\mathrm{Oh}$ used as a basis for developing the algorithm of soil moisture retrieval with neural networks (NNs) computational model. Two NNs is used as a universal regression technique to establish the relationship between scattering anisotropy, entropy and backscattering coefficients measured by the Sentinel-1B on the one hand and reflectivity on the other. Finally, the soil moisture was found from the soil reflectivity in solving the inverse problem using the Mironov dielectric model. During the field campaign from 21 May to 25 August 2020, it was shown that the proposed approach allows us to predict soil moisture values in the layer thickness of $0.00-0.05 \mathrm{~m}$ with the root-mean-square error and determination coefficient not worse than $3 \%$ and 0.726 , respectively. The validity of the proposed approach needs additional verification on a wider dataset using soils of different textures, a wide range of variations in soil surface roughness, and moisture.
\end{abstract}

Keywords: microwave remote sensing; Sentinel-1; bare soil; soil moisture; soil permittivity

\section{Introduction}

The roughness and moisture of bare agriculture soil are key parameters that influence backscattering signatures measured by the Sentinel- 1 at a frequency of $5.4 \mathrm{GHz}$ at a fixed viewing angle. Soil moisture retrieved using the well-known Oh, Dubois, and integral equation (IEM) backscattering models, as a rule, lead to a significant mismatch compared to soil moisture values, measured at the sub-satellite test sites [1,2]. For bare soil, the main reason for this is the multi-scale spatial variety of the heights of soil surface roughness, which changes dynamically with time. According to [3], the standard deviation, the correlation length, and the autocorrelation function of the heights of soil surface roughness depend not only on roughness but also on the size of the data collection profile $(0.5-25 \mathrm{~m})$. This fact leads to the practical inexpediency of the ground-based measurements of soil surface roughness statistical characteristics as input parameters of existing scattering models and the development on their basis of global multi-scale radar remote sensing soil moisture algorithms. However, to take into account the specific local characteristics of soil 
surface roughness in articles [4,5], correlation length was proposed to calibrate depending on the root mean square (RMS) heights of soil surface roughness and viewing angles. Such calibrated models are widely used for training artificial neural networks (NNs) [6-8]. The trained $\mathrm{NN}$ on physical-based scattering models [6-8] is more adaptive compared to simply training the NN with Sentinel-1 backscattering and ancillary soil moisture values [9-12].

In this paper, the relationship between the cross-polarized ratio, reflectivity, and the soil surface roughness, established in [13], was proposed to use as a basis for the soil moisture retrieval algorithm from Sentinel-1 radar data. Compared to IEM, Advanced IEM, and Dubois models, the Oh model [13] shows the best fitting between its predictions and representative experimental radar dataset over bare soils [1]. In contrast to existing physical-based approaches [6,7], in this paper, the well-known linear relationship between root-mean-square (RMS) heights of soil surface roughness and scattering anisotropy [14-17] was used to predict soil reflectivity based on NN and Oh models [13]. As a result, only satellite data and in situ soil moisture values on the key test site were needed to calibrate the $\mathrm{NN}$, but the ground measurements of soil surface roughness could be excluded. It should be noted that the linear relationship between RMS heights of soil surface roughness and scattering anisotropy was observed over a wide frequency range [17] from 1.5 to $18 \mathrm{GHz}$, which include C-band radar of Sentinel-1.

\section{Test Site, Remote Sensing, and In Situ Data}

The fallow agricultural field of $100 \times 100 \mathrm{~m}$, located near the Minino village, Krasnoyarsk region, the Russian Federation was chosen as a test site (Figure 1).

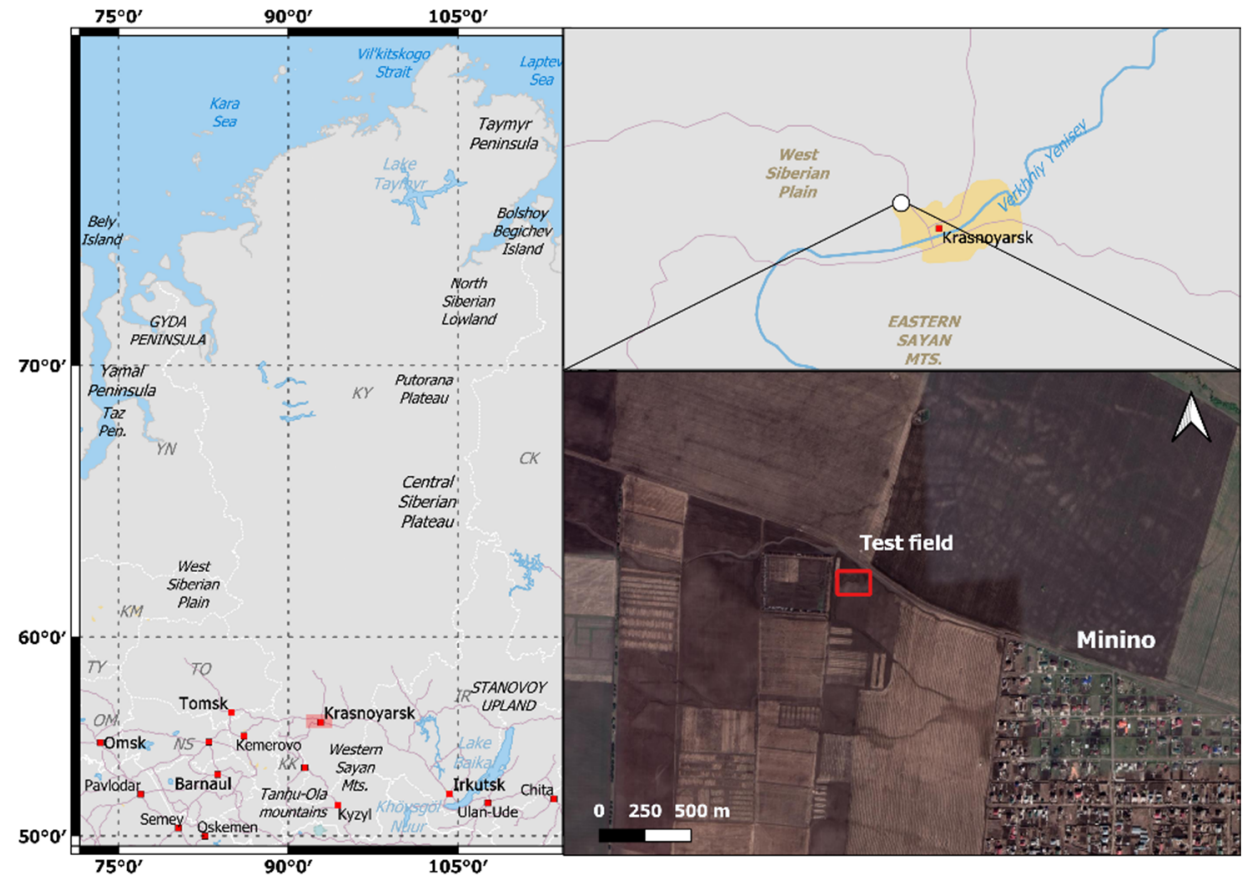

Figure 1. Location of the test field.

The center of the agriculture field locates in coordinate $\left(56.0865^{\circ} \mathrm{N}, 92.6772^{\circ} \mathrm{E}\right)$. In days of Sentinel-1B passage (from 21 May to 25 August of 2020 every twelve days) soil moisture was measured in the $0.00-0.05-\mathrm{m}$ top layer at $23-27$ small local plots $(\sim 8-10 \times 8-10 \mathrm{~m})$ evenly scattered within the agricultural field and separated from each other by a distance of $\sim 10-12 \mathrm{~m}$. Soil moisture was measured in 40-80 separate points evenly distributed in each small local plots. After that, they were averaged. As a result, for each day of Sentinel1B observations, sets of geospatial soil moisture data were obtained for 23-27 small local plots within the agricultural field. The center of each small local plot was assigned a GPS coordinate. Volumetric soil moisture was measured by EC-5 sensor (Decagon, Pullman, 
WA, USA). The sensor was vertically immersed into the soil to the length of the entire rods $(0.05 \mathrm{~m})$. The sensor was equipped with a NEO-M8N GPS receiver providing positioning in the horizontal plane with an error of $\sim 2 \mathrm{~m}$. The sensor was calibrated in laboratory conditions using soil samples collected on the test field. After calibration, RMS error (RMSE) of volumetric soil moisture measurements by EC- 5 did not exceed $2 \%$ (with determination coefficient $R^{2}=0.99$ ) in the soil moisture range from 6 to $50 \%$. (High moisture values were obtained with additional moisturized of soil samples). The soil cover of the agriculture field is represented by the Haplic Chernozems soils [18]. Average dry bulk density and clay content in the topsoil thickness of about $0.05 \mathrm{~m}$ were $0.93-1.16 \cdot 10^{3} \mathrm{~kg} \mathrm{~m}^{-3}$ and about $26 \%$ (by weight), respectively.

The Sentinel-1B radar data were available in interferometric wide (IW) swath mode (10-m special resolution) on vertical-vertical (VV) and vertical-horizontal (VH) polarizations. Single look complex (SLC) and ground range-detected (GRD) images were processed by the European Space Agency (ESA) Sentinel Application Platform (SNAP). Standard processing of the Sentinel-1 radar data consisted of: precision orbits applied, calibration, and speckle noise filtering (Gamma map filter with a window size of $3 \times 3$ pixels), rangeDoppler terrain correction (SRTM 1Sec HGT). As a result, for the agriculture field, spatial maps of backscattering coefficients $\sigma_{\mathrm{VV}}, \sigma_{\mathrm{VH}}$, alpha angle, scattering anisotropy $A$, and entropy $H$ [14] were obtained. The incidence angle of wave was about $37^{\circ}$. Due to the mismatch between the coordinates of Sentinel-1B pixels and small local plots, the backscattering coefficients corresponding to the center of each small local plots were calculated using the spatial linear interpolation of Sentinel-1B image. As a result, from 21 May to 25 August 2020, the total amount of joint observations data of backscattering coefficients and soil moisture was 159 .

During the experiments, the agriculture field was harrowed several times (the distance between the harrows and their heights were about $0.2-0.3 \mathrm{~m}$ and about $0.07-0.12 \mathrm{~m}$, respectively). Even though the agriculture field was in the same place and was harrowed several times, the surface roughness and moisture content of soil were different for each day of Sentinel-1B observations due to natural moisturization by rain, drying and wind erosion. This statement is supported by the carried out polarimetric analysis based on the $\mathrm{H}-\alpha$ decomposition [14] using complex images of the test field at two polarizations $\mathrm{VH}$ and VV (Figure 2).

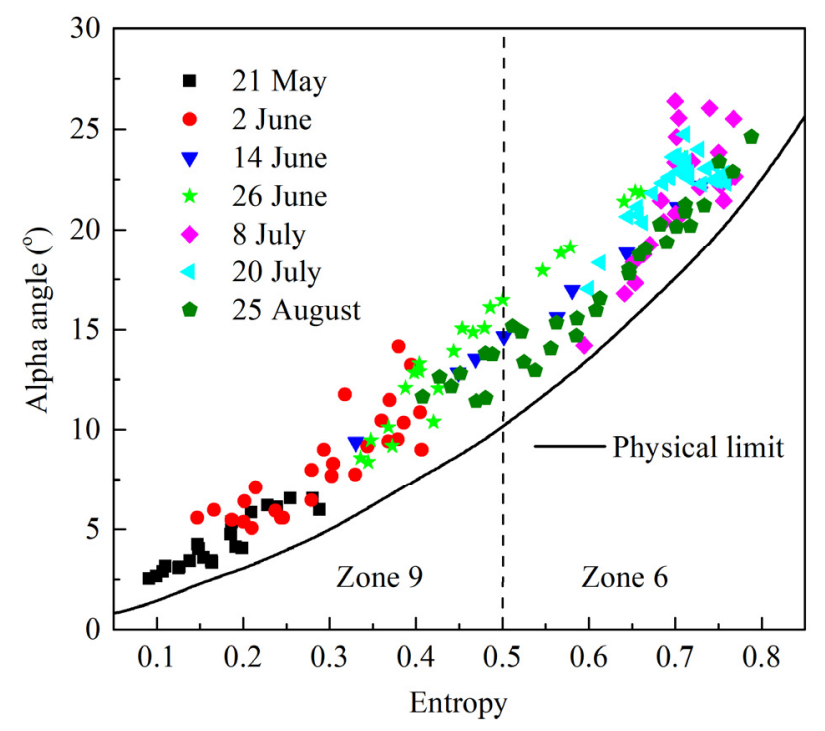

Figure 2. Characterization of the small local plots based on $\mathrm{H}$ - $\alpha$-decomposition. The solid line marks the boundary of physically significant results of $\mathrm{H}-\alpha$ decomposition in accordance with [14].

Despite the close high soil moisture values on June 2 and August 25 (Table 1), H- $\alpha$ decomposition shows that the points corresponding to observations on August 25 are 
scattered sufficiently higher than those on June 2 (Figure 2) because after ploughing of the soil surface roughness increased (Table 1).

Table 1. Test field moisture and tillage statistics averaged overall small local plots.

\begin{tabular}{ccccc}
\hline \multirow{2}{*}{ Date } & \multicolumn{3}{c}{ Soil Moisture [\%] } & \multirow{2}{*}{ 1 Ploughed } \\
\cline { 2 - 4 } & Mean & Min & Max & \\
\hline 21 May & 9.6 & 7.4 & 12.8 & No $^{2}$ \\
2 June & 22.3 & 15.6 & 24.7 & No \\
14 June & 17.1 & 15.4 & 18.7 & No \\
26 June & 10.9 & 7.6 & 16.5 & Yes \\
8 July & 11.8 & 9.4 & 18.6 & No \\
20 July & 11.2 & 7.7 & 13.2 & Yes \\
25 August & 22.6 & 17.3 & 26.8 & Yes \\
\hline
\end{tabular}

${ }^{1}$ Whether the field was ploughed again before the date of measurements. ${ }^{2}$ Unlike other days, ploughing of the test field took place until 21 May (more than 12 days earlier).

On 21 May, the soil showed the lowest degree of roughness (since ploughing was more than 12 days earlier) and was driest for the entire observation period (Table 1), determining the position of scattered points near the origin in the H- $\alpha$ diagram. In the H- $\alpha$ diagram (Figure 2), the scattered points corresponding to 26 June, 8 July, and 20 July lie higher than those were for 21 May, although these soil moisture values were close (Table 1). This could be explained by the significant change of the soil surface roughness as the test field was several times ploughed in this period (Table 1). Data in Figure 2 evidence that the scattered waves undergo a single-diffuse scattering by the soil surface of varying degrees of roughness and moisture, as the variations of alpha angle and scattering entropy were significant.

\section{Soil Moisture Retrieval Method Using NNs and Polarimetric Sentinel-1B Data}

In accordance with well-known radar scattering models, in the general case, the backscattering coefficient can be represented as the product of two functions, one of which depends on soil moisture, the other on the surface roughness parameters (RMS height and correlation length) [12]. In the case of the semi-empirical backscattering model (Equation (4) [13]), the cross-polarized ratio $q=\sigma_{\mathrm{VH}} / \sigma_{\mathrm{VV}}$ normalized on Fresnel reflectivity of the surface at nadir-viewing $\Gamma_{0}(\varepsilon(W))$ depends on the RMS height of soil surface roughness $h_{\mathrm{r}}$ exponentially:

$$
\frac{q}{0.23 \sqrt{\Gamma_{0}(\varepsilon(W))}}=\left(1-\exp \left(-k_{0} h_{\mathrm{r}}\right)\right),
$$

where $\varepsilon(W)$ is the complex permittivity of soil with volumetric moisture of $W, k_{0}$ is the free space wavenumber, $k_{0} h_{\mathrm{r}}$ is a dimensionless quantity characterizing the RMS height of soil surface roughness in wavenumbers of free space, $\sigma_{\mathrm{VH}}$ and $\sigma_{\mathrm{VV}}$ are backscattering coefficient at $\mathrm{VH}$ and VV polarizations. The semi-empirical backscattering model (Equation (4) [13]) was created based on polarimetric radar measurements, which were conducted for bare soil surfaces under a very wide range of roughness from $h_{\mathrm{r}}=0.004 \mathrm{~m}$ to $h_{\mathrm{r}}=0.0302 \mathrm{~m}$ (from $k_{0} h_{\mathrm{r}}=0.10$ to $\left.k_{0} h_{\mathrm{r}}=6.01\right)$, correlation length, $l$, from $k_{0} l=2.6$ to $k_{0} l=17.5$, and volumetric moisture from $9 \%$ to $31 \%$ (soil surface), and it combined frequencies in $L(1.5 \mathrm{GHz}), C$ $(4.75 \mathrm{GHz})$, and $X(9.5 \mathrm{GHz})$ bands at incidence angles ranging from 10 to $70^{\circ}$. Note that the roughness of the soil surface was collected over ten 1-m and two 3-m profiles for each surface. The articles [14-17] show that the scattering anisotropy $A$ was insensitive to the variation of soil permittivity and the angle of observation at $k_{0} h_{\mathrm{r}}<1$, and the linear relationship between $A$ and $k_{0} h_{\mathrm{r}}$ (at $h_{\mathrm{r}}=0.004 \mathrm{~m}$ and ranges of frequencies from 1.5 to $18.5 \mathrm{GHz}$ ) was observed. Note that in [19], based on the RADARSAT-2 experimental data, it was shown that $A$ has a linear dependence on $h_{\mathrm{r}}$ only in the range of $k_{0} h_{\mathrm{r}}<1.2\left(h_{\mathrm{r}}<0.011 \mathrm{~m}\right.$ at a frequency of $5.4 \mathrm{GHz}$ ). 
The right and left sides of Equation (1) can be calculated using: (1) $q$ values (measured by Sentinel-1B from 21 May to 25 August 2020 at the agriculture field for different small local plots); (2) reflectivity $\Gamma_{0}(\varepsilon(W))$, calculated based on the dielectric model [20] and experimental soil moisture values, measured at the small local plots within the agriculture field; (3) assuming [17]:

$$
k_{0} h_{\mathrm{r}} \sim 1-A
$$

There is a robust linear relationship (coefficient of determination $R^{2}=0.597$ ) between the left and right sides of Equation (1), but there are significant random deviations from it (Figure 3).

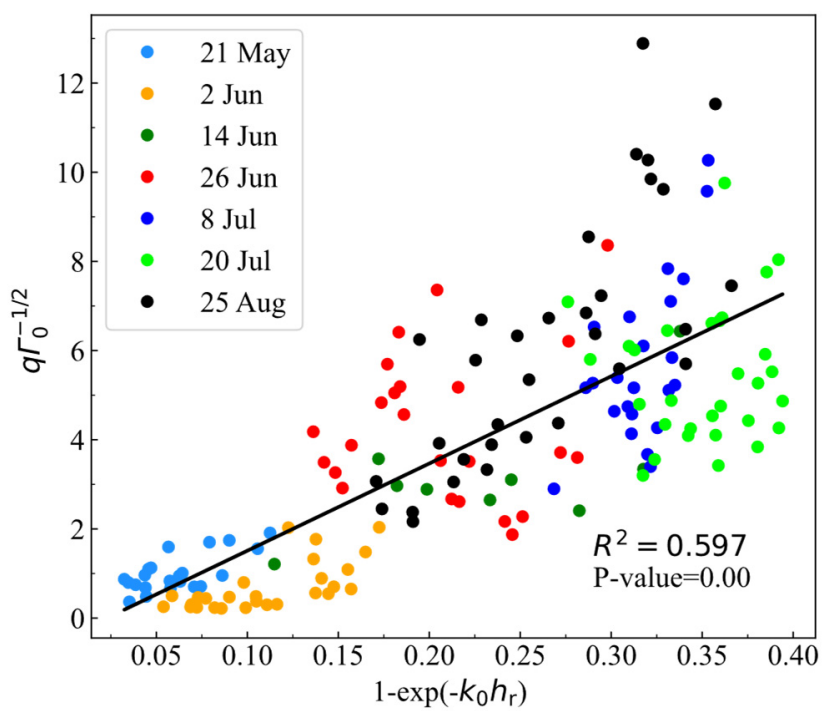

Figure 3. Correlation between the left and right side of Equation (1) for different days of Sentinel-1B observation. ( $R^{2}$ is the determination coefficient). In this calculation, $k_{0} h_{\mathrm{r}}$ was assumed equal to $1-A\left(k_{0} h_{\mathrm{r}}=1-A\right)$.

These random deviations are explained by the limited ability of the scatter model (1) and relation (2) to describe the surface roughness caused by different scale topography. In addition, that discrepancy can be explained by the influence of speckle noises on the measured values of the backscattering coefficient $\sigma_{\mathrm{VH}}, \sigma_{\mathrm{VV}}$ and the anisotropy $A$. Based on the above analysis, we will introduce two NNs to retrieve soil moisture (Figure 4 ). The simplest feed-forward NNs, consisting of from one to two hidden layers, were used. NN modeling was performed in the Matlab 2013 software environment (Mathworks, MA, USA). The first neuron network $\mathrm{NN}_{1}$ implemented the connection between the anisotropy $A$ and some functional $\zeta_{1}^{\text {out }}\left(h_{r}\right)=q \Gamma_{0}^{-p}$ that, according to model (1), depends only on the soil surface roughness. As a result, the estimate of soil reflectivity $\Gamma_{0}^{\mathrm{NN}_{1}}=\left(q / \zeta_{1}^{\text {out }}\right)^{1 / p}$ (with the weakened influence of soil roughness) could be obtained on the basis of the $\zeta_{1}^{\text {out }}$, value predicted by the first neural network $\mathrm{NN}_{1}$. However, due to the fact that the simple model (1) and the assumption of (2) do not fully describe the relationship between crosspolarized ratio $q$, Fresnel reflectivity, and soil surface roughness (Figure 3), the second $\mathrm{NN}_{2}$ was used (Figure 4) to predict the reflectivity $\zeta_{2}^{\text {out }}=\Gamma_{0}^{\mathrm{NN}_{2}}$ with using the extra parameter of scattering entropy $H\left(\zeta_{2}^{\text {in }}=H\right)$, which carried additional information about roughness and moisture of soil [17]. 

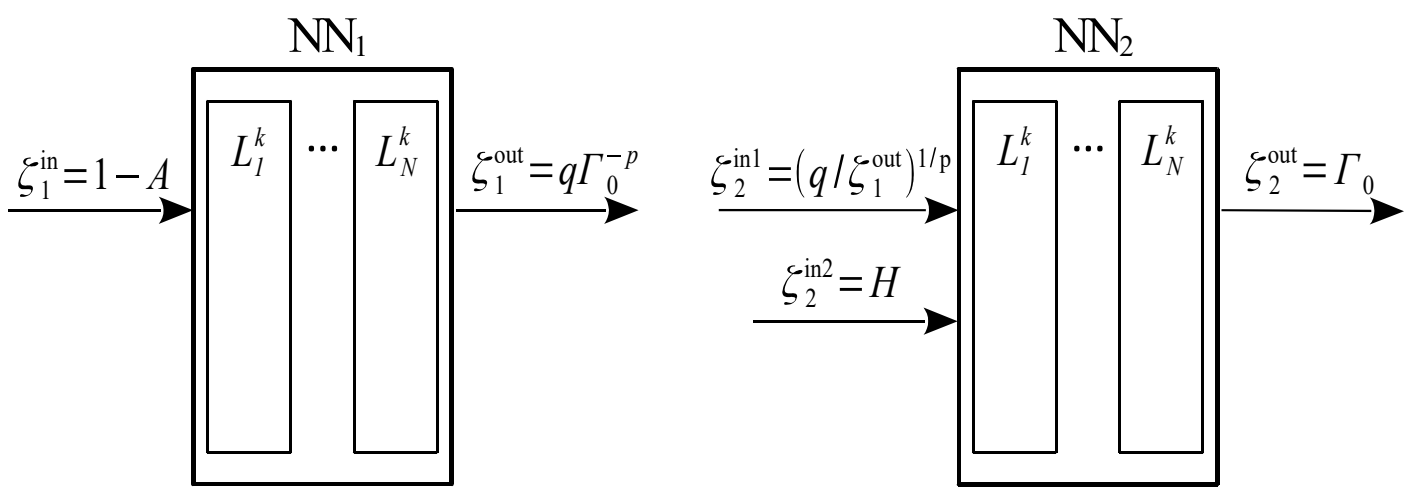

Figure 4. Feedforward network $\mathrm{NN}_{1}$ and $\mathrm{NN}_{2}$ with $\mathrm{N}$ hidden layers and $k$ neurons in each, where $k=1, \ldots, n$.

In our case of bare soil, scattering entropy $H$ and angle alpha were unambiguously related, so we chose only $H$. (On the entropy/alpha plane (Figure 2), the data points located along the azimuthal symmetry line in ninth and sixth zones.) As a result, as input parameters of NNs were used $\left\{1-A,\left(q / \zeta_{1}^{\text {out }}\right)^{2 / 3}, H\right\}$. The value $\Gamma_{0}(\varepsilon(W))$ was used as an output parameter. To train NNs, we used reflectivities $\Gamma_{0}(\varepsilon(W))$, calculated based on a dielectric model [20] and soil moisture, measured in the 0.00-0.05 $\mathrm{m}$ layer at the small local plots within the agriculture field from 21 May to 25 August 2020 every twelve days (at the time of Sentinel-1B passages). The NNs were trained on $60 \%$ of the dataset, which corresponded to 95 small local plots randomly selected from all datasets. During the training of NNs, the inverse problem to determine the optimal parameter $p$ using Levenberg-Marquardt algorithm [21] was also solved. In the first $L_{1}^{k}$ and second $L_{2}^{k}$ hidden layers, the number of neurons, $k$, varied from 1 to $n=120$ and from 1 to $n=30$, respectively (Figure 5a). Both NNs were the same and consisted of an equal number of hidden layers and neurons. Numerical experiments have shown that it is sufficient to use only one hidden layer $L_{1}^{k}$ in each neural network with more than $k=40$ neurons and extent $p$ equal 1.5 to achieve $R^{2} \sim 0.89$ (at RMSE less than 0.105 ) between predicted NNs and calculated (based on experimental soil moisture data) reflectivity values $\Gamma_{0}(\varepsilon(W))$ (Figure $5 \mathrm{~b}$ ). As can be seen from Figure $5 \mathrm{~b}$, it was at $p$ near 1.5 that a maximum of $R^{2}$ was observed (this maximum was observed for the different variants of neural networks structures: $L_{1}^{k}, L_{1}^{k} L_{2}^{10}$, $\left.L_{1}^{k} L_{2}^{30}\right)$.
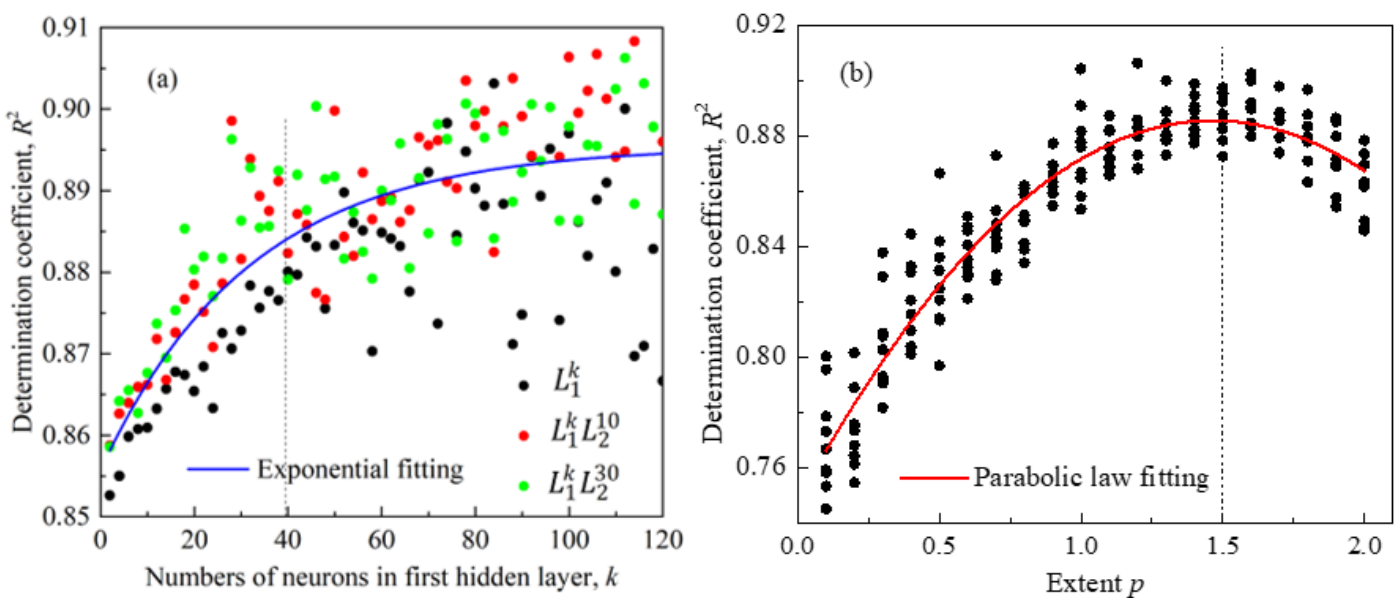

Figure 5. Determination coefficient between predicted by NNs $\zeta_{1}^{\text {out }}$ and target values $q \Gamma_{0}^{-p}(\varepsilon(W))$ depend on (a) $k$ numbers of neurons in case of one hidden layer $L_{1}^{k}$, two hidden layers $L_{1}^{k} L_{2}^{10}$ and $L_{1}^{k} L_{2}^{30}$ with 10 and 30 neurons in the second hidden layer (at $p=1.5$ see dash line on Figure 5 b), (b) extent $p$ in case one hidden layer with $k=40$ neurons $L_{1}^{40}$ (see dash line on Figure 5a). 
In the course of further numerical analysis, one hidden layer with 40 neurons $L_{1}^{40}$ was used in each neural network. At the last step, the inverse problem of soil moisture determination from predicted reflectivity by NNs was solved using the permittivity model [20] and Levenberg-Marquardt algorithm [21].

\section{Results and Discussion}

The described process of soil moisture retrieval was applied to validate the created methodology based on the total amount of data (the joint observations of backscattering coefficients and soil moisture) that took and did not take part in training NNs. The correlation between predicted and measured soil moisture values at the small local plots on the agricultural field from 21 May to 25 August 2020 is depicted in Figure 6. Two NNs $\left(\mathrm{NN}_{1}\left(L_{1}^{40}\right)\right.$ with input parameter $1-A$ and $\mathrm{NN}_{2}\left(L_{1}^{40}\right)$ with input parameters $\Gamma_{0}^{\mathrm{NN}_{1}} \equiv\left(q / \zeta_{1}^{\text {out }}\right)^{2 / 3}$ and $H$ (Figure 4) predicted soil moisture values with RMSE $=3 \%$ and $R^{2}=0.726$, relative to ground trough measurements (Figure 6). (These estimates were derived using all datasets).

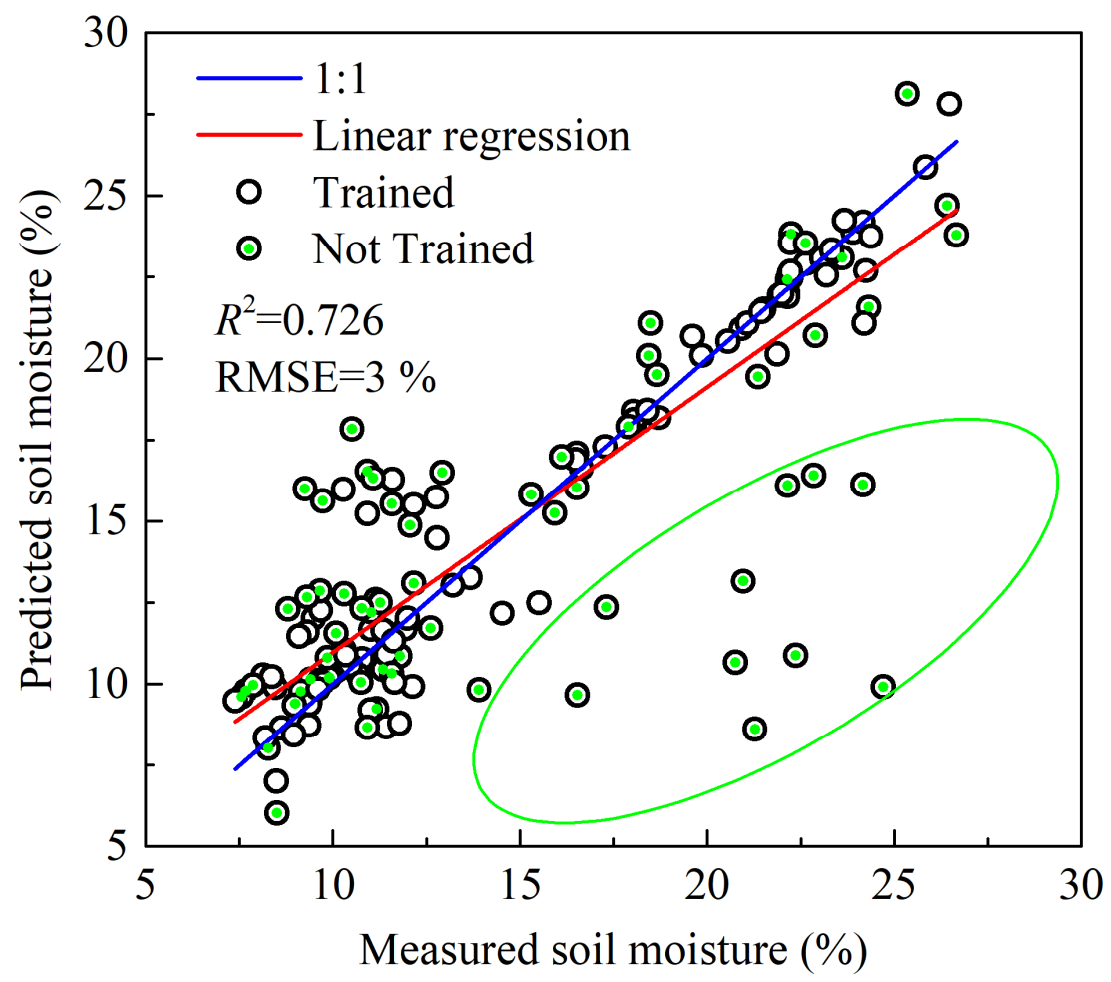

Figure 6. Predicted NNs soil moisture from Sentinel-1B observations versus soil moisture, measured at the small local plots from 21 May to 25 August 2020. The 159 circle symbols refer to 159 small local plots of the test field, on which soil moisture was measured in days of Sentinel-1 passes. Green ellipse is associated with small local plots that did not participate in NNs training and related to 25 August.

The dispersion (Figure 6, green ellipse) was associated with small local plots that did not participate in NNs training and related to 25 August (statistically atypical day during the field campaign, when the soil surface was strongly wetted by rains the day after ploughing). For example, Figure 7a shows the map of the retrieved soil moisture values from Sentinel-1B using the proposed approach for the test field on 26 June 2020. The RMSE and $R^{2}$ between the retrieved and measured soil moisture values on 26 June 2020 over the entire test area were $2 \%$ and 0.819 , respectively (Figure 7 ). In this case, the maximum absolute deviations of the retrieved from the measured soil moisture values reached $-6 \%$ and $+3 \%$ (Figure $7 \mathrm{~b}$ ). 

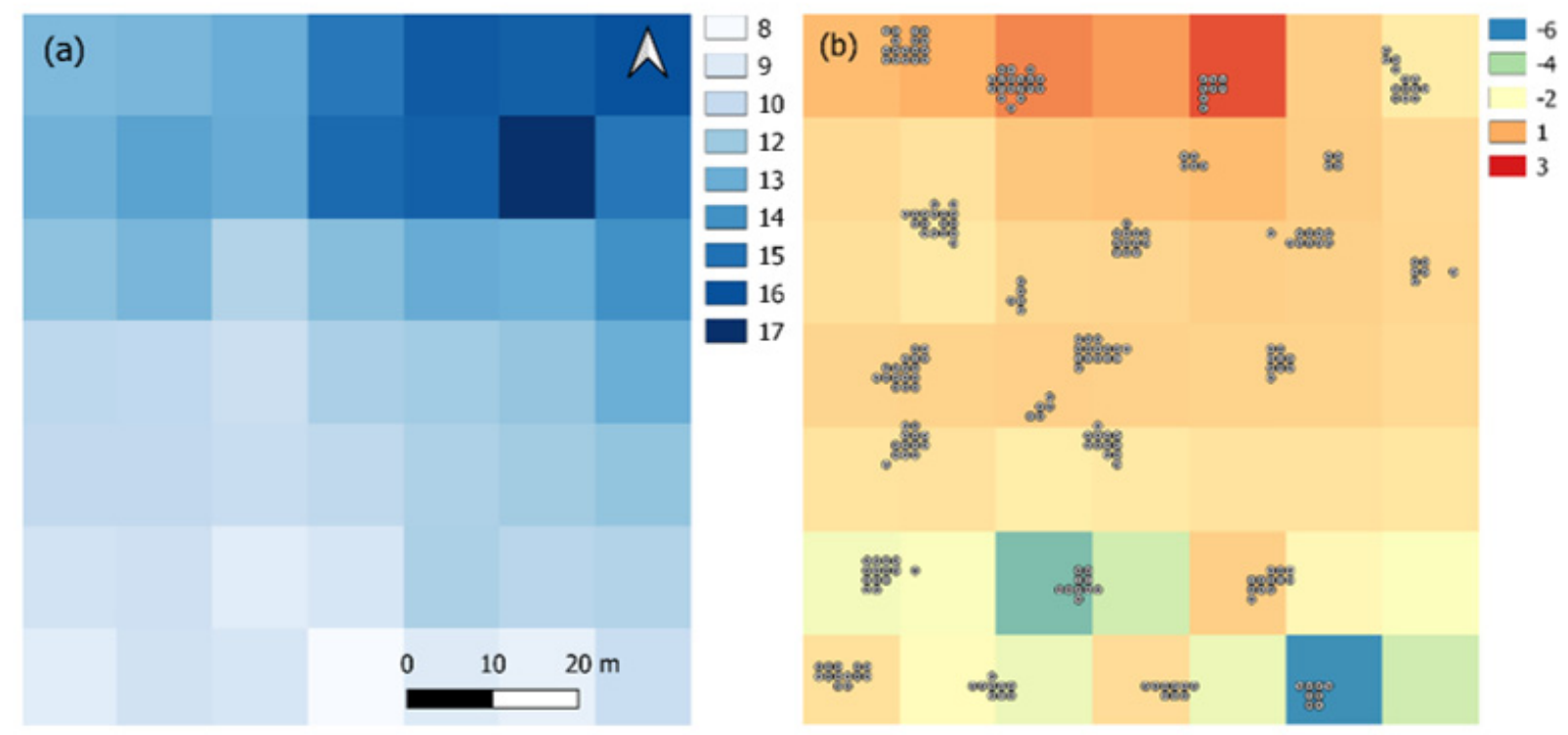

Figure 7. Predicted NNs soil moisture from Sentinel-1B observations (a), the difference between predicted NNs and measured in situ soil moisture values (b) on 26 June 2020 at the test field. In situ measurements of soil moisture at the small local plots within agriculture field depicts as points on panel (b). In the legends, the absolute values of soil moisture and the difference values of soil moisture are given in \%. These maps were obtained from retrieved by NNs and measured in local plots soil moisture values using inverse distance weighted interpolation on the square grid with approximately $10 \mathrm{~m}$.

It should be noted that in this particular case, there was a tendency to overestimate/underestimate the retrieved soil moisture values for more wet/dry areas of the test field.

\section{Conclusions}

The case study showed the promise of using neural networks to retrieve surface moisture of bare soil from Sentinel-1B observations. At this, NNs can be used to build adaptive physical-based relationships between soil surface roughness parameter (in our case, the soil surface roughness determined based on the Oh model), reflectivity, and polarimetric scattering characteristics such as anisotropy and entropy. At the same time, in contrast to the physical-based methods [2,6,7], there is no need for ground-based information on soil surface roughness. Applying such a combined approach, only ground-based measurements of soil moisture to calibrate the scattering model using NNs were required. One of the disadvantages of the proposed method is the neglect of satellite observation angle. However, according to [13], the angular dependences of backscattering coefficient from bare soil weakly depend on the observation angle in the range from 25 to $50^{\circ}$. The impact of this factor has to be studied for test fields located at significant distances from each other. It should be noted that the proposed method was tested on one kind of soil, and it is needed additional verification in various landscape with different soils texture, roughness and moisture conditions.

Author Contributions: K.M. completed most of the works on the data treatment and modeling; A.Z. conceptualized and designed the framework of this study. Both authors have read and agreed to the published version of the manuscript.

Funding: This work was supported by the Russian Foundation for Basic Research (grant No. 19-29$05261 \mathrm{mk}$ ). The field experiment and EC-5 Decagon sensor calibration in laboratory conditions were carried out with the support of Ministry of Science and Higher Education of the Russian Federation, project No. 0287-2021-0034 (basic state assignment).

Conflicts of Interest: The authors declare no conflict of interest. 


\section{References}

1. Choker, M.; Baghdadi, N.; Zribi, M.; El Hajj, M.; Paloscia, S.; Verhoest, N.E.C.; Lievens, H.; Mattia, F. Evaluation of the Oh, Dubois and IEM Backscatter Models Using a Large Dataset of SAR Data and Experimental Soil Measurements. Water 2017, 9, 38. [CrossRef]

2. Baghdadi, N.; Zribi, M. Evaluation of radar backscatter models IEM, OH and Dubois using experimental observations. Int. J. Remote Sens. 2006, 27, 3831-3852. [CrossRef]

3. Davidson, M.W.J.; Le Toan, T.; Mattia, F.; Satalino, G.; Manninen, T.; Borgeaud, M. On the characterization of agricultural soil roughness for radar remote sensing studies. IEEE Trans. Geosci. Remote Sens. 2000, 38, 630-640. [CrossRef]

4. Baghdadi, N.; King, C.; Chanzy, A.; Wigneron, J.P. An empirical calibration of the integral equation model based on SAR data, soil moisture and surface roughness measurement over bare soils. Int. J. Remote Sens. 2002, 23, 4325-4340. [CrossRef]

5. Panciera, R.; Tanase, M.A.; Lowell, K.; Walker, J.P. Evaluation of IEM, Dubois, and Oh Radar Backscatter Models Using Airborne L-Band SAR. IEEE Trans. Geosci. Remote Sens. 2014, 52, 4966-4979. [CrossRef]

6. Ayehu, G.; Tadesse, T.; Gessesse, B.; Yigrem, Y.M.; Melesse, A. Combined Use of Sentinel-1 SAR and Landsat Sensors Products for Residual Soil Moisture Retrieval over Agricultural Fields in the Upper Blue Nile Basin, Ethiopia. Sensors 2020, $20,3282$. [CrossRef] [PubMed]

7. Mirsoleimani, H.R.; Sahebi, M.R.; Baghdadi, N.; El Hajj, M. Bare Soil Surface Moisture Retrievalfrom Sentinel-1 SAR Data Based on the Calibrated IEM and Dubois Models Using Neural Networks. Sensors 2019, 19, 3209. [CrossRef] [PubMed]

8. El Hajj, M.; Baghdadi, N.; Zribi, M.; Bazzi, H. Synergic Use of Sentinel-1 and Sentinel-2 Images for Operational Soil Moisture Mapping at High Spatial Resolution over Agricultural Areas. Remote Sens. 2017, 9, 1292. [CrossRef]

9. Paloscia, S.; Pettinato, S.; Santi, E.; Notarnicola, C.; Pasolli, L.; Reppucci, A. Soil moisture mapping using Sentinel-1 images: Algorithm and preliminary validation. Remote Sens. Environ. 2013, 134, 234-248. [CrossRef]

10. Hachani, A.; Ouessar, M.; Paloscia, S.; Santi, E.; Pettinato, S. Soil moisture retrieval from Sentinel-1 acquisitions in an arid environment in Tunisia: Application of Artificial Neural Networks techniques. Int. J. Remote Sens. 2019, 40, 9159-9180. [CrossRef]

11. García, G.A.; Venturini, V.; Brogioni, M.; Rodríguez, E.W.L. Soil moisture estimation over flat lands in the Argentinian Pampas region using Sentinel-1A data and non-parametric methods. Int. J. Remote Sens. 2019, 40, 3689-3720. [CrossRef]

12. Li, Y.; Yan, S.; Chen, N.; Gong, J. Performance Evaluation of a Neural Network Model and Two Empirical Models for Estimating Soil Moisture Based on Sentinel-1 SAR Data. Prog. Electromagn. Res. C 2020, 105, 85-99. [CrossRef]

13. Oh, Y.; Sarabandi, K.; Ulaby, F. An empirical model and an inversion technique for radar scattering from bare soil surfaces. IEEE Trans. Geosci. Remote Sens. 1992, 30, 370-381. [CrossRef]

14. Cloude, S. The dual polarisation entropy/alpha decomposition: A PALSAR case study, Proc. 3rd Intern. In Proceedings of the Workshop on Science and Applications of SAR Polarimetry and Polarimetric Interferometry (POLinSAR), Frascati, Italy, 22-26 January 2007; pp. 1-6.

15. Cloude, S.R.; Hajnsek, I.; Papathanssiou, K.P. An Eigenvector Method for the Extraction of Surface Parameters in Polarimetric SAR. In Proceedings of the ESA CEOS SAR Workshop, ESA SP-450, Toulouse, France, 26-29 October 1999. Available online: http:/ / adsabs.harvard.edu/pdf/2000ESASP.450..693C (accessed on 8 August 2021).

16. Cloude, S.R.; Lewis, G.D. Eigenvalue analysis of Mueller matrices for bead-blasted aluminum surfaces. SPIE 2000, 4133, 4114-4133.

17. Hajnsek, I.; Pottier, E.; Cloude, S.R. Inversion of surface parameters from polarimetric SAR. IEEE Trans. Geosci. Remote Sens. 2003, 41,727-744. [CrossRef]

18. Shpedt, A.A.; Trubnikov, Y.N.; Zharinova, N.Y. Agrogenic degradation of soils in Krasnoyarsk forest-steppe. Eurasian Soil Sci. 2017, 50, 1209-1216. [CrossRef]

19. Baghdadi, N.; Cresson, R.; Pottier, E.; Aubert, M.; Zribi, M.; Jacome, A.; Benabdallah, S. A potential use for the C-band polarimetric SAR parameters to characterise the soil surface over bare agriculture fields. IEEE Trans. Geosci. Remote Sens. 2012, 50, 3844-3858. [CrossRef]

20. Mironov, V.L.; Karavayskiy, A.Y.; Lukin, Y.I.; Molostov, I.P. A dielectric model of thawed and frozen Arctic soils considering frequency, temperature, texture and dry density. Int. J. Remote Sens. 2020, 41, 3845-3865. [CrossRef]

21. Gill, P.E.; Murray, W. Algorithms for Nonlinear Least-Squares Problem. SIAM J. Numer. Anal. 1978, 15, 977-992. [CrossRef] 